\title{
MUITO ANTES DE AÏ-KHANOUM: A REPRESENTAÇÃO HISTORIOGRÁFICA DA BÁCTRIA HELENÍSTICA NAS LIÇÕES DE HISTÓRIA ANTIGA DE BARTHOLD NIEBUHR
}

\author{
Fábio Augusto Morales (UFSC) ${ }^{1}$ \\ Santiago Colombo Reghin (UFSC) $)^{2}$
}

\begin{abstract}
Resumo
O presente artigo trata das representações historiográficas da Báctria helenística nas Lições de História Antiga de Barthold Niebuhr, ministradas na Universidade de Bonn na década de 1820 e publicadas em alemão e inglês na década de 1850. Após um panorama do quadro atual das pesquisas sobre a Báctria Helenística, revolucionado pelas escavações francesas nas décadas de 1960 e 1970, o artigo explora o modo como Niebuhr, diante de um então pouco documentado objeto histórico, articula crítica documental, raciocínio demográfico, moral e racial, e os debates políticos contemporâneos. O artigo conclui com uma síntese da discussão, defendendo a necessidade da historicização das sínteses historiográficas tanto do século XIX quanto as atuais, especialmente no contexto da História Global.
\end{abstract}

\section{Palavras-Chave}

Historicismo alemão; Báctria helenística; Aï Khanoum; Niebuhr; História Global.

\footnotetext{
1 Professor Doutor - Universidade Federal de Santa Catarina, Florianópolis, Brasil. Email: fabio.morales@ufsc.br

2 Graduado em História - Universidade Federal de Santa Catarina, Florianópolis, Brasil. E-mail: santiago_tj96@hotmail.com
}

Heródoto, Unifesp, Guarulhos, v.4, n.1 - 2019.1 p. 103-121

DOI: 10.34024/herodoto.2019.v4.10089 


\begin{abstract}
This paper deals with the historiographical representation of Hellenistic Bactria in Barthold Niebuhr's Lectures on Ancient History, based on lectures given at Bonn University in the 1820's and published in German and English in the 1850's. The first part offers a panorama of archaeological, epigraphic and numismatic research after the great French excavations in Afghanistan in the 1960 and 1970's. The second part discusses how Niebuhr, facing a poorly documented Bactrian history and archaeology, articulate source criticism, demographic, moral and racial reasoning and contemporary political debate. The paper concludes with a summary of the discussion, arguing for the necessity of historicization of historiographical syntheses as well in nineteenth century as today, especially in the context of Global History.
\end{abstract}

\title{
Keywords
}

German historicism; Hellenistic Bactria; Aï Khanoum; Niebuhr; Global History. 
Seja do ponto de vista semi-global, pois sua história conecta processos originados no Mediterrâneo, na Sibéria, no Irã, na Índia, na China e nas estepes centro-asiáticas, seja do ponto de vista regional e local, pois suas cidades e assentamentos demonstram como as diferentes globalizações antigas foram integradas a partir de arranjos próprios, a Báctria no período helenístico é atualmente um dos objetos mais ricos para aqueles interessados nos temas e questões da História Global. Às esparsas referências na tradição literária e alguns conjuntos de moedas cunhadas na região, foram somados, nas últimas décadas, extraordinários conjuntos documentais que incluem desde assentamentos urbanos intensa e extensamente escavados, como Aï Khanoum e o santuário de Takht-i Sangin, às centenas de assentamentos rurais e protourbanos repertoriados em prospecções de superfície. A grande quantidade de estudos sobre a Báctria helenística aponta para novas perspectivas tanto em questões mais circunscritas, como a cronologia e história política do reino greco-báctrio, quanto mais amplas, como a análise das conexões inter-regionais e das interações multiétnicas nas esferas econômica, cultural, política, militar, religiosa etc. Em poucas palavras, a história e a arqueologia da Báctria helenística é um laboratório privilegiado para a história das globalizações antigas, uma das vias da promissora História Global (Morales; Pereira, 2019; Knust, 2019; Scopacasa, 2018)

As questões centrais debatidas pelos estudiosos, entretanto, derivam mais da história da formação do campo da História Helenística do que da agenda dos estudos globais contemporâneos. No centro do debate, está o problema da extensão e da avaliação dos efeitos dos contatos helenísticos em relação às comunidades locais, sintetizado sob a rubrica do "processo de helenização": desde meados do século XIX, estudiosos têm defendido visões opostas, que variam na avaliação tanto de sua influência na vida das populações não-gregas, quanto da agência destas no processo. Sem dúvida, tais questões são também centrais para a História Global, hoje ainda centrada nos períodos moderno e contemporâneo, ainda que diversos estudos apontem para um maior diálogo com a História Antiga (Hodos, 2014; Vlassopoulos, 2016; Burstein, 2017; Knust, 2019; Scopacasa, 2018; Morales; Silva, 2019). De todo modo, é fundamental ter em mente o modo como tais questões foram construídas no âmbito específico da História Helenística para, então, articula-las aos debates mais amplos da recente História Global.

O objetivo deste artigo é analisar o tratamento dado a estas questões por uma das primeiras sínteses da moderna História Antiga, a saber, as Lições de História Antiga (Vörtrage über alte Geschichte) de Barthold Niebuhr, tomando como estudo de caso sua representação da Báctria - muito antes 
da revolução documental produzida pelas escavações francesas a partir dos anos 1960. Responsável pela organização da moderna História Antiga em função da Tradição Clássica (Morales, no prelo) e pelo estabelecimento do método histórico de crítica documental, Niebuhr dedicou seu primeiro curso na Universidade de Bonn, em 1823, à "História Geral Grega Tardia" (Ueber die Spätere Griechisch Geschichte im Allgemeinen), que correspondia aos séculos IV e I a.C.; anotações e transcrições das 31 aulas do curso seriam publicadas em alemão em 1851 e em inglês no ano seguinte, como terceiro volume de suas Lições. A Báctria é tratada de modo marginal, algo não surpreendente antes da fascinante descobertas em Aï Khanoum, nos anos 1960 e 1970, que fizeram a região ocupar um lugar de destaque nas introduções à História Helenística, como no recente livro de Peter Thonemann (2016). Não obstante, a representação historiográfica do limite oriental do mundo helenístico em Niebuhr revela os conceitos e procedimentos morfológicos adotados para resolver questões centrais, tais como: qual era a unidade do mundo helenístico, e como ela se revelava em sua fronteira? Como conhecer e discutir os efeitos do processo de helenização, neste contexto? Os severos desafios metodológicos envolvidos na análise das fragmentárias fontes para a história bactriana que já foram definidos como o "teste supremo da História, Arqueologia e Numismática" (Holt, 1999, p. 9) - deram suporte a especulações de natureza racial, cultural e econômica produzidas em função dos modelos elaborados por cada autor: as lacunas bactrianas, pois, revelam com mais clareza os limites e as possibilidades das visões de cada autor acerca do mundo helenístico.

Assim, o artigo inicia com uma apresentação panorâmica da pesquisa recente sobre a Báctria helenística, de modo a tornar mais claro o movimento algo tateante de Niebuhr sobre um objeto revolucionado pelas pesquisas arqueológicas da segunda metade do século XX. Em seguida, passamos à discussão do modelo explicativo proposto por Niebuhr, articulando as representações da Báctria às concepções mais amplas sobre o mundo helenístico, vinculadas a agendas políticas e sociais específicas. Por fim, concluímos o artigo apresentando a síntese dos pontos discutidos ao longo do texto e apontando caminhos frutíferos do diálogo entre a História Helenística e a História Global, considerando a massa de trabalho acumulado na historiografia. 


\section{A Báctria na História Helenística recente}

Entre o planalto iraniano, as montanhas do vale do Indo e as estepes da Ásia central, a Báctria helenística foi um espaço para trocas culturais e econômicas entre diferentes populações: persas, iranianos, tajiques, gregos, indianos e yuezhis interagiram de diferentes maneiras, da guerra à paz, da convivência à submissão imperial. A profusão de fontes encontradas nas pesquisas recentes inclui centros urbanos, assentamentos dispersos, inscrições, moedas, estátuas, cerâmica e estruturas arquitetônicas; a quantidade massiva de dados disponíveis ainda estão em processamento, e as interpretações ainda são constantemente revistas (Aldrovandi, 2010; Mairs, 2016). Neste sentido, a Báctria helenística é um laboratório tanto para a articulação interdisciplinar (entre História, Arqueologia, Numismática e História da Arte), quanto para a discussão de problemas centrais para os estudos diretamente influenciados pelo processo contemporâneo de globalização capitalista, dentre os quais a História Global é dos mais recentes e estruturados.

A posição assumida pela Báctria helenística no campo da História Antiga, no entanto, é recente: o caráter lacunar dos conjuntos documentais até a segunda metade do século XX gerou o movimento duplo de extrema cautela nos estudos acadêmicos e de liberdade literária na escrita ficcional (Holt, 1999). O cenário, entretanto, mudaria radicalmente com a descoberta, acidental, da cidade helenística de Aï Khanoum (MartinezSève, 2015). Cobrindo uma superfície triangular de cerca de 100 ha, o sítio de Aï Khanoum localiza-se na atual fronteira entre o Afeganistão e o Tajiquistão, no ponto em que o rio Oxus recebe as águas de seu tributário rio Kokcha, no coração da Báctria oriental. A importância do sítio, conhecido desde o século XIX, somente foi totalmente compreendida após o início das escavações francesas, realizadas após a descoberta de colunas coríntias pelo séquito do então rei afegão Muhammad Zaher Shah, que caçava na região no ano de 1961. A convite do rei, a Délégation Archéologique Française en Afghanistan conduziu as escavações entre 1964 e 1978, quando a guerra do Afeganistão contra a União Soviética impediu sua continuidade. O primeiro volume da série Fouilles d'Aï Khanoum aparece em 1973; o mais recente, nono da série, foi publicado em 2013. A publicação detalhada do material encontrado tornou-se particularmente importante após os reiterados saques ao sítio e ao museu de Kabul durante os anos de guerra.

As campanhas revelaram uma cidade com muitos edifícios de tipo grego, tais como propileus, muros e fortificações, um palácio, residências, santuários, tumbas, um ginásio e um teatro - o único a leste da Babilônia. 
Além dos edifícios, uma imensa quantidade de cerâmica, escultura, joalheria, moedas e inscrições revelaram detalhes da cultura, administração e da relação com os não-gregos por parte da colônia grega. Um dos exemplos mais impressionantes é a famosa inscrição descoberta em 1966 no santuário do fundador Cineas (Robert, 1968; Holt, 1999: 37-47; Verhasselt, no prelo). A inscrição diz que Clearco, identificado por estudiosos como Clearco de Soli, discípulo de Aristóteles, trouxe de Delfos as máximas gravadas em uma estela colocada acima de uma base, o único elemento conservado; provavelmente por motivo de espaço, a última máxima foi inscrita na própria base, onde se lê: "quando criança, aprenda boas maneiras; quando jovem, controle suas paixões; quando adulto, seja justo; quando velho, dê bons conselhos; diante da morte, sem tristeza" (Verhasselt, no prelo: 9). A inscrição e sua localização apontam para um projeto de reforço da identidade grega do local, referenciada ao santuário pan-helênico de Delfos, pelos primeiros colonizadores gregos que fundaram a cidade entre o final do século IV e início do III a.C. Não obstante, a presença de diversos elementos não-gregos na paisagem urbana da cidade, especialmente seus santuários com templos de nichos e seu palácio com amplo pátio peristilo, chamaram a atenção dos estudiosos para as interações com a população local.

Aï Khanoum é o principal, mas não o único sítio bem documentado da Báctria helenística. Um santuário na colina Takht-i Sangin, que faz face ao tio Oxus (e provavelmente dedicado à sua forma divinizada), apresenta elementos orientais e gregos na planta e na elevação; o material votivo inclui estátuas gregas, cerâmica, moedas, objetos de marfim e a maior coleção de armas helenísticas já encontrada (Litvinskiy; Pichikiyan, 1981).

As descobertas de Aï Khanoum e Takht-I Sangin, especialmente as inscrições em pedra e moedas, permitiram uma reconstituição mais precisa da história política bactriana no século III e II a.C. O numismata Frank Holt, baseado em fontes literárias, arqueológicas e numismáticas, produziu uma narrativa a partir das relações entre a Báctria, a corte selêucida e os poderes vizinhos (Holt, 1999). Conforme o autor, após um primeiro assentamento na época de Alexandre, Selêuco I enviou seu filho Antíoco I como vice-rei na satrapia da Báctria, como forma de conter as tendências desertistas dos primeiros colonizadores; Antíoco desenvolveu o processo de colonização e fundou a primeira casa de cunhagem da região. Sob Diodotos I, sátrapa da Báctria, a região atravessou um longo período de paz e prosperidade entre as décadas de 280 e 240 , no qual o sátrapa acumulou cada vez mais poder e autonomia em relação à corte. Um evento fundamental neste processo foi a expulsão do líder nômade Arsaces, que havia se estabelecido na Báctria na década de 250 e depois da expulsão seguiria para a satrapia 
vizinha da Pártia, onde, posteriormente, fundaria seu próprio reino; possivelmente ligado a este evento, Diodotos I começa a gravar seu retrato em moedas que, não obstante, ainda carregam o nome do rei selêucida. A sucessão de Diodotos I por seu filho, Diodotos II, por volta de 240, marca a independência da Báctria em relação à corte selêucida. A contestação por um rival local, Eutidemo, provavelmente levou Diodotos II a se aliar a Arsaces da Pártia; o conflito entre Diodotos II e Eutidemo se resolveu em cerca de 225, quando a Aï Khanoum é invadida e tem início a nova dinastia eutidêmida. A expedição de Antíoco III à fronteira oriental do império, no final do século III, reforça a suserania formal da corte selêucida sobre a Báctria, sem, contudo, o retorno à sua condição de satrapia. O reino da Bácria mantém sua independência até cerca de 150, quando a região é invadida pelas tribos nômades Yuezhi, que havia migrado para a Sogdiana e a Báctria após os conflitos com o império chinês; as últimas menções a reis da Báctria datam da década de 130.

Sob os diodótidas, de acordo com Holt, a Báctria se tornou muito mais do que apenas corredor entre a Índia e o Mediterrâneo. As cunhagens diodótidas, especialmente as séries em bronze, revelam muitas dimensões da interação econômica e cultural entre gregos e não-gregos. Um exemplo eloquente é a assimilação da deusa grega Ártemis à deusa iraniana Anahita (Holt, 1999: 121-3): ambas associadas à lua, à vida selvagem e ao parto, Ártemis/Anahita dividiram a iconografia monetária com Zeus, tomado como deus dinástico ("Diodotos", i.e., presente de Zeus). Holt inclusive sugere que Ártemis/Anahita era a deusa políade de Aï Khanoum, cujo nome significa, na língua tajique, "Deusa Lua". A ausência do cão, um símbolo comum na iconografia monetária de Ártemis, é interpretada por Holt como um cuidado dos monarcas tomado para não associar erroneamente a deusa aos cultos locais relacionados aos cães, considerados abomináveis pelos gregos desde a passagem de Alexandre.

A exploração arqueológica de sítios monumentais tais como Aï Khanoum e Takht-i Sangin, entre os anos 1960 e 1980, foi conduzida de acordo com um método centrado na valorização da arquitetura, da epigrafia e da arte: estruturas individuais, inscrições e materiais com valor estético foram meticulosamente descritos em longos relatórios publicados pela DAFA, com uma notável preferência por monumentos gregos (Aldrovandi, 2010). Entretanto, no final dos anos 1970, campanhas arqueológicas baseadas na prospecção de superfície (surveys) começam a ser realizada no vale do Oxus, sob a direção de Jean-Claude Gardin (Gentelle, 1989; Lyonnet, 1997; Gardin, 1998), enfatizando aspectos da história regional negligenciados pelas primeiras missões, tais como distribuição da cerâmica, soluções de irrigação e padrões de assentamento. As prospecções de superfície, 
guiadas pelos sistemas de irrigação, revelaram uma paisagem muito mais ampla no espaço e no tempo: as campanhas prospectaram $200 \mathrm{~km}^{2}$ na planície de Dasht-i Qala, revelaram 350 sítios, e $1500 \mathrm{~km}^{2}$ na Báctria oriental, revelando 474 sítios. A cronologia proposta pelos arqueólogos distingue cinco fases, do Neolítico ao período islâmico. O período helenístico corresponde à quarta fase; segundo os arqueólogos, ele não representou uma transformação profunda nos padrões de assentamento e nos sistemas de irrigação, definidos ainda na primeira fase. Tratou-se, antes, da ampliação das redes já existentes, desenvolvendo padrões de crescimento estabelecidos no período aquemênida (Aldrovandi, 2010).

As prospecções de superfície na Báctria oriental, realizadas entre 1974 e 1978, publicadas entre 1989 e 1998, alteram profundamente os parâmetros tanto da pesquisa sobre a região quanto sobre a compreensão das relações entre sociedades no coração da Eurásia no período helenístico. O impacto da helenização foi sensivelmente reduzido: quando contrapostos a um quadro cronológico e geográfico mais amplo, a criação da colônia grega de Aï Khanoum e os quase duzentos anos de domínio grego na região, mais do que transtornar, reforçaram e ampliaram padrões já estruturados em períodos anteriores, e que se manteriam em períodos posteriores. Diante disso, a reavaliação do próprio significado da helenização se torna fundamental: mais do que a implantação de um enclave de helenidade diante de uma multidão de nativos mais ou menos resistentes, o reino Greco-Báctrio passa a ser visto como parte da história da relação das populações locais com impérios e formas culturais estrangeiras (Aldrovandi, 2010). O conceito de helenização, em movimento análogo ao experimentado pelo conceito de romanização (Morales, 2014), integra as e é integrado pelas - histórias locais, não-gregas. O paradigma da continuidade das estruturas aquemênidas e próximo orientais no período helenístico, formulada em primeiro lugar por M. Rostovtzeff e defendida com vigor por Pierre Briant, aos poucos torna-se hegemônico (Briant, 2015). Tal movimento, pois, se articula claramente com a difusão das perspectivas pós-coloniais no âmbito das ciências humanas entre o final do século XX e início do XXI, situando as experiências imperialistas europeias no centro da organização dos paradigmas acerca do período helenístico (Alcock, 1994; Aldrovandi, 2010).

Esta reorientação joga nova luz sobre as pesquisas realizadas sobre Aï Khanoum, em particular, na medida em que o paradigma de uma helenização "pura" levou os arqueólogos a negligenciarem sítios e traços não-gregos na cidade e em seus arredores. A "cidade circular" aquemênida de Kohna Qala, a $2 \mathrm{~km}$ do sítio e os elementos arquitetônicos e urbanísticos não-gregos presentes na malha urbana, por exemplo, são indicadores de 
uma possível história prévia aquemênida do sítio (Aldrovandi, 2010; Mairs, 2014).

A pesquisa sobre os sítios monumentais de Aï Khanoum e Takht-i Sangin, por um lado, e sobre os padrões espaciais de ocupação do território da Báctria como um todo, por outro, são campos abertos para a experimentação historiográfica e arqueológica, tanto no sentido metodológico, para o processamento dos dados e síntese das interpretações do nível das fontes, quanto morfológico, para a compreensão do sentido das fronteiras temporais e espaciais do período helenístico (Aldrovandi, 2010). Afinal, a Báctria helenística, disputada pela História da Grécia e pela História da Índia no século XX (Holt, 1999: 12), parece assumir cada vez mais seu lugar eurasiático inserida na longa duração da ocupação do território e da interação entre macrorregiões antecipando, então, as rotas da Seda.

Este movimento recente, pois, dialoga com estruturas bem estabelecidas da historiografia, guiada por agendas e conceitos ligados ao problema da helenização tal como formulado no século XIX e ampliado no século XX. As múltiplas pesquisas particulares acerca de conjuntos documentais definidos e as sínteses históricas regionais, objeto de escrutínio da bibliografia especializada, ao mesmo tempo influenciaram e foram influenciadas pelos modelos historiográficos mais amplos produzidos sobre o sentido do período helenístico. Destes modelos, destacamos dois particularmente importantes na conformação do campo, a saber, os propostos por Niebuhr e Droysen. Passemos, pois, ao modo como a Báctria é representada nestas sínteses fundadoras da História Helenística.

\section{A Báctria de Niebuhr: decadência, raça e império}

Nascido em 1776 na cidade de Copenhagen, Barthold Niebuhr era filho do célebre explorador, matemático e cartógrafo Carstein Niebuhr, cujas viagens e pesquisas no Irã lhe renderam um lugar especial na decifração da escrita cuneiforme. Criado recluso em uma casa repleta de livros de história, geografia e filologia, além do consumo constante da nascente imprensa, B. Niebuhr estudaria Direito e Filosofia na Universidade de Kiel em 1794, quando, segundo suas cartas, já estava decidido a seguir a carreira filológica. Após trabalhar como contator na burocracia do estado dinamarquês e de realizar viagens à Inglaterra e Escócia, em 1810 ingressa na Universidade de Berlim como professor de História Romana, cargo que deixaria logo em 1813 para ingressar no exército prussiano na guerra contra a França napoleônica. O período na Universidade de Berlim, cujo 
primeiro reitor foi o filósofo e ativista anti-napoleônico J. G. Fichte, levou Niebuhr a entrar no debate entre a História e a Filosofia do Direito representadas, respectivamente, por F. de Savigny e W. Hegel, também professores em Berlim. A importância deste debate é dificilmente superestimada: estava em questão a relação entre o direito prussiano e os sistemas jurídicos das várias comunidades germânicas no processo de formação do Estado Nacional alemão, assim como o próprio conceito de História (Iggers, 2012, p. 66). A contribuição de Niebuhr ao debate, ao lado da História, envolveu a elaboração do método histórico de crítica documental, utilizado prioritariamente na análise de Tito Lívio e sua discussão sobre as leis romanas; a descoberta do ager publicus no Direito Romano é uma de suas realizações mais influentes, tocando diretamente o problema da natureza e origem da propriedade privada (Momigliano, 1982). Os resultados das pesquisas de Niebuhr seriam publicados em sua História de Roma já em 1811, livro que trouxe fama ao autor e a seu método.

Após um longo período de serviço público e diplomático para o estado prussiano, Niebuhr retornaria à atividade universitária em 1823, tornandose professor de História Antiga na Universidade de Bonn - cargo que ocuparia até sua morte, em 1831. Seu primeiro curso foi dedicado à "história geral grega tardia", ou seja, ao período entre o século IV e a conquista romana; posteriormente, ofereceu cursos sobre o período clássico e a história pré-clássica, além de cursos sobre geografia e etnografia da Antiguidade. As anotações dos cursos, suas e de seus alunos, foram postumamente publicadas como Lições de História Antiga, das quais as aulas sobre a "história geral grega tardia" correspondem ao terceiro volume. No prefácio da obra das Lições, Niebuhr explica suas escolhas morfológicas: a Antiguidade se dividiria em História Antiga e História Romana, sendo a primeira centrada na história dos gregos e seus contatos. Baseava-se no uso como textos-guia das obras de Tito Lívio e de Pompeu Trogo, as últimas sumarizadas por Justino (Niebuhr, 1852a: 33-45). Se Tito Lívio estruturava a narrativa a partir da História de Roma, Pompeu Trogo o fazia a partir da história grega, evitando Roma - o que levou estudiosos a desconfiarem de um "anti-romanismo" de Trogo, ao invés de uma muito mais plausível escolha narrativa não-romanocêntrica em função da história romanocentrada de Lívio. As duas histórias seriam unidas por Niebuhr, e a "história tardia dos gregos" seria o momento final da História Antiga antes de ser incorporada à História Romana. As Lições, então, foram publicadas em três volumes, o primeiro contexto as discussões metodológicas gerais e a História Antiga anterior ao período clássico (Niebuhr, 1852a), o segundo concentrado no período clássico (Niebuhr, $1852 b)$, e o terceiro ao período posterior (Niebuhr, 1852c). Aqui, utilizamos a tradução inglesa, cotejada com o original em alemão. 
Não é aqui o espaço para analisarmos em detalhe as escolhas metodológicas e narrativas de Niebuhr para a História Antiga como um todo, tema desenvolvido em outro texto (Morales, 2019); aqui, nos concentraremos nas representações sobre a Báctria em seus registros de aula. No entanto, vale destacar que Niebuhr não rompe com o topos narrativo da "decadência moral dos gregos" diante da expansão do poder macedônico (Briant, 2005; Payen, 2005), representados como não-gregos por Niebuhr. Cruéis e despóticos tal como os contemporâneos turcos, os macedônios construíram um império sobre as cidades gregas sufocando suas aspirações à liberdade. Demóstenes, por exemplo, em sua luta contra Filipe da Macedônia, é elogiado como último defensor da liberdade, diante da afirmação de uma época em que as intrigas de corte tomariam o lugar histórico das decisões de assembleias e conselhos (Niebuhr, 1852c: 41-46). O paralelo Macedônia/Império Otomano é complementado, ainda, por uma associação com a França Napoleônica: a política e a cultura das cidades gregas poderiam ser comparadas às das cidades prussianas sob e logo após a dominação estrangeira (Niebuhr, 1852c: 54).

O tom lamentoso da decadência política e moral dos gregos no período em questão não impediu que Niebuhr apresentasse análises e narrativas históricas extremamente ricas e complexas, acerca de temas históricos bastante variados. Longe do "mito historiográfico" que anacronicamente representa diversos historiadores alemães do século XIX como "positivistas", Niebuhr intercalava narrativas políticas e militares com análises sobre arte, moral e economia, baseando-se tanto nas fontes escritas quanto em fontes arquiteturais e numismáticas, quando disponíveis. As engenhosas discussões das fontes eram associadas a diferentes objetivos de acordo com o tema central. Quando tratava das fronteiras orientais das conquistas macedônicas, a questão central discutida por Niebuhr era, invariavelmente, a unidade imperial e a natureza e limites da penetração da cultura grega nas sociedades "asiáticas".

O tema da unidade imperial, vale dizer, já aparece na menção à Báctria prémacedônica, feita no segundo volume (dedicado ao período clássico). De acordo com Niebuhr, ao contrário do século V a.C., quando "a Índia, no vale do Indo, pertencia à Pérsia, e a Báctria era uma das principais províncias", na época de Alexandre a "Báctria era tão fragilmente conectada com o império, que seus sátrapas podiam facilmente tornar-se independentes, e a Índia juntamente foi perdida" (Niebuhr, 1852b: 233). O problema da independência provincial, assim, existia já durante as últimas décadas do Império aquemênida, e continuaria na era pós-alexandrina, como veremos. 
No terceiro volume das Lições abundam as menções à Báctria, especialmente no contexto das discussões sobre a monarquia selêucida, usando como fonte fragmentos de Políbio, Estrabão, Pompeu Trogo [Justino] e Apiano. A primeira menção ocorre na discussão sobre o reinado de Antíoco I. Para Niebuhr, embora a primeira impressão seja a de que Antíoco tenha estendido os domínios de seu pai e antecessor, Selêuco I, a natureza do poder imperial havia mudado profundamente. De acordo com o autor, muitas regiões do império, "as quais seu pai lhe legou em estado de submissão, afirmaram sua independência", tais como a Capadócia, o Ponto, a Armênia e a Báctria, que "se tornou independente sob um rei macedônio". Niebuhr iguala independência a subordinação formal, argumentando que Antíoco I "foi obrigado a se satisfazer com a manutenção da supremacia nominal naquelas regiões" (Niebuhr, 1852c: 283). A manutenção deste estado de coisas, bem como a existência de um rei macedônico, entretanto, assegurava a continuidade de instituições gregas. O contra-exemplo vinha dos estados indianos, "os quais, tendo se separado do império, retornaram às suas próprias instituições nacionais" (Niebuhr, 1852c: 283). A tensão independência/supremacia nominal continuaria por mais de um século até que Antíoco III, o qual, "embora não fosse de modo algum um grande homem, recebeu de seus cortesãos, não sem razão, o título de 'o Grande', porque ele restaurou o império [contra] o estado de fermentação e desorganização" da Ásia superior (Niebuhr, 1852c: 298). Em outra passagem, Niebuhr compara a fragilidade da autoridade selêucida àquela do Sultanato otomano: "em territórios distantes, como, por exemplo, a Báctria, a autoridade dos reis sírios era tão pouco respeitada quanto aquela do Sultão em Bagdá ou no Egito" (Niebuhr, 1852c: 346). O paralelo é retomado em uma conclusão acerca do império selêucida no contexto da independência da Báctria e da Pártia no século III a.C.:

As províncias setentrionais, que pertenciam ao Coração (Khorassan), poderiam ter se submetido à dinastia grega dos príncipes báctrios, se elas não fossem já dominadas pelos partos. Uma grande parte do império sírio, que de acordo com nossas percepções era um vasto império, permaneceu; mas ele era fraco em virtude da divisão por satrapias, e isso levou ao mesmo estado de dissolução que existe no império turco diante dos pachas: cada satrapia tinha o poder em suas mãos para fazer a independência (Niebuhr, 1852c: 347).

Os maiores inimigos do império selêucida, pois, eram seus sátrapas; a "supremacia nominal" somente criou a aparência de um império, quando na realidade a divisão e a fraqueza eram a regra. Os agentes da divisão eram, ironicamente, as cidades fundadas por Alexandre e os reis selêucidas justamente para reforçar a unidade. Niebuhr oferece uma explicação demográfica e racial para isso: as cidades greco-macedônicas, ao invés de 
promover a helenização dos povos asiáticos, foram inversamente asianizadas por eles. Vale a pena citar a passagem integralmente:

Embora estas cidades estivessem no meio de terras barbaras, elas ainda
mantinham suas instituições gregas. Eram repúblicas com suas politeiai, etc., e tais
espaços republicanos existiam das costas do Mediterrâneo até o interior do país.
O número de habitantes era bem pequeno em relação aos asiáticos circundantes,
e mesmo assim o número de gregos e macedônios afluindo para estas cidades
drenou a Europa, de modo que a Grécia e Macedônia estavam consequentemente
desertas. Casando-se com mulheres asiáticas, surgiu uma nação de natureza
mista, como a meia-casta da Índia e os pullan das cruzadas. Tais povos mistos
têm um caráter próprio: a meia-casta indiana, os mulatos, os mestiços, apesar de
não se distinguirem por sua cor, poderiam facilmente ser reconhecidos por sua
natureza. Eles são ativos, animados e ligeiros, mas carecem de confiabilidade pela
sua educação asiática. Quando crianças eles são bonitos, têm mente aberta e
aprendem fácil, mas não vão além da mediocridade. Tais estados, com língua
grega degenerada e com a forma de uma república, que frequentemente não tem
existência real, que não recebe fluxos apenas de gregos e macedônios, mas em
grande medida de asiáticos também, continuaram a existir no tempo dos
Sassânidas, 500 anos depois. [...] Esses estados deveriam servir como pontos para
manter o governo das províncias um pouco mais estáveis, mas, pelo contrário,
causaram revoltas nas províncias. Os assim chamados gregos, macedônios e
gregos, não foram tão puros na Ásia quanto em Alexandria, onde a língua grega
era falada de modo mais puro pelo trafego marítimo direto (Niebuhr, 1852c: 299-
301).

O argumento demográfico, segundo o qual a migração, mesmo tendo deixado a Grécia e a Macedônia "desertas", não foi suficiente para fazer frente à maioria asiática, está na base da explicação: a raça mista, resultado do casamento interracial, gerou cidadãos potencialmente traiçoeiros, os quais, apesar da existência de formas institucionais gregas, não eram gregos puros - por oposição à "mediterrânica" Alexandria. As cidades "gregas" orientais, ao invés de assegurar a submissão das províncias, levaram às insurreições contra o império. A natureza inferior dos asiáticos é retomada ainda na avaliação da "grandeza" de Antíoco III, vencedor nas campanhas na Ásia "tão longe quanto a fronteira da Báctria", mas vencido por Roma no lado mediterrânico: "se ele não tivesse lutado contra Roma, seu reino seria bastante ilustre na história; entretanto, seu poder foi grande somente contra asiáticos" (Niebuhr, 1852c: 347).

Não obstante, Niebuhr reconhece o papel destas cidades na difusão e permanência da cultura grega. Após afirmar a influência da cultura grega sobre a cultura sassânida, Niebuhr articula a Báctria ao debate sobre as semelhanças entre a filosofia indiana e a grega. Após fazer coro à recusa da tese de uma origem indiana da filosofia grega, Niebuhr sugere que não se pode compreender "as semelhanças [entre as filosofias indiana e grega], exceto situando-as na conexão entre os indianos e os reis greco- 
macedônicos da Báctria" (Niebuhr, 1852c, p. 300). A presença da cultura grega na fronteira oriental, no entanto, se limitaria às suas influências sobre as culturas que a sucederam, como as de indianos e partos: mesmo a Báctria perderia sua helenidade. Independente do império selêucida, o reino greco-macedônico da Báctria, junto das satrapias da Babilônia, Hircânia e Média, seria incorporado ao império arsácida da Pártia; então, para Niebuhr, a "Ásia novamente tornou-se completamente asiática" (Niebuhr, 1852c: 466).

Em síntese, a representação historiográfica da Báctria helenística em Niebuhr - um reino distante povoado por uma raça mista, com adesão parcial à cultura grega e mesmo ao império, que influenciaria outras culturas mas não seria capaz de manter a helenidade da região - servia, em sua obra, para discutir problemas mais amplos como a relação entre unidade cultural e unidade política e os riscos da miscigenação étnicoracial. No âmbito da decadência moral observada na "história tardia dos gregos", a unidade política dependia da unidade étnico-racial; sua ausência nas fronteiras significou a submissão a outros povos e o desaparecimento da cultura grega.

Dado o paralelo entre a "Grécia tardia" e a Prússia do início do século XIX, não nos parece exagero associar as reflexões de Niebuhr aos debates intensos travados, no meio universitário alemão, a respeito das dimensões jurídica, militar e racial da formação de um estado nacional alemão capitaneado pelo reino prussiano (Breuilly, 2007, 2008). A ambiguidade entre o elogio da liberdade das cidades gregas contra o império macedônico (associado ao Império Turco e ao Napoleônico), por um lado, e a crítica ao fracasso macedônio na manutenção de seu império (por oposição a Roma), por outro, poderia significar uma relação ambígua de Niebuhr diante do projeto prussiano de unificação nacional ainda em construção nos anos 1820. A associação entre Napoleão e Filipe II, em particular, fez parte da retórica do renascimento da "nação alemã" contra a ocupação francesa, fortemente inspirado em Demóstenes (Canfora, 2007). De todo modo, a natureza mesma da obra - anotações de aulas - serve como um antídoto à busca de um sistema absolutamente coerente: os paralelos que o professor Niebuhr faz entre a Antiguidade e a Modernidade não são sistemáticos, aparecendo ali e aqui em função de suas escolhas didáticas, sem necessariamente um planejamento prévio. 


\section{Considerações finais}

A história e a arqueologia da Báctria helenística, revolucionada pelas descobertas e estudos do último meio século, há muito atraiu a atenção dos estudiosos: fronteira oriental do mundo helenístico, suas exíguas e fragmentadas fontes disponíveis antes das escavações dos anos 1960 obrigaram historiadores a expor as potências e fragilidades de seus paradigmas para a construção de sínteses coerentes. Neste texto, selecionamos uma das primeiras sínteses produzidas de acordo com o paradigma moderno de História Antiga, a saber, as Lições de História Antiga de Barthold Niebuhr. Com isso, pudemos observar como paradigmas gerais sobre o período helenístico se adequavam a esta situação limite, no sentido tanto geográfico e quanto metodológico. Resultado dos cursos de Niebuhr sobre a "história geral grega tardia", representava a Báctria como um reino macedônico asianizado, sintoma da decadência geral helenística: a crueldade macedônica se uniria ao caráter traiçoieiro dos asiáticos, o que levava necessariamente à secessão em relação ao império selêucida; não obstante, a Báctria deixou um legado de helenidade, visível nos paralelos entre a filosofia grega e a cultura budista. $\mathrm{O}$ fracasso do empreendimento imperial selêucida se deu pela miscigenação com a raça asiática, inferior moralmente.

A representação historiográfica da Báctria em Niebuhr, ainda que dependente de suas escolhas metodológicas no contexto de uma severa escassez de fontes, dialoga profundamente com sua experiência das transformações sociais e políticas da Europa no início do século XIX. Testemunha da derrota e depois da vitória sobre o exército napolêonico, Niebuhr acompanhou a reconstrução do estado prussiano sob os escombros das estruturas anteriores; a unificação, embora no horizonte, era menos impactante para sua visão do período helenístico do que a experiência da opressão napoleônica. O paralelo da Prússia com Atenas e da França com a Macedônia - assim como a representação extremamente positiva de Demóstenes - demonstram a pertinência do paradigma da decadência e do fim liberdade para a história grega e para a história prussiana.

Certamente, a interação entre demandas do presente e interpretação historiográfica não são exclusivas do século XIX: as novas histórias da Báctria também se relacionam com transformações culturais e geopolíticas profundas. Por um lado, a crítica ao helenocentrismo na história da região se articula com a difusão das abordagens pós-coloniais e decoloniais derivadas dos processos de independência da segunda metade do século $\mathrm{XX}$; por outro, os estudos sobre as interações culturais de diferentes etnias 
do centro da Afroeurásia respondem a emergência dos estudos globais e do próprio processo de globalização, especialmente diante da ascensão chinesa. De qualquer modo, é perceptível que tais preocupações já apareciam na síntese de Niebuhr. A grande ruptura do ponto de vista da documentação disponível após Aï Khanoum, pois, se articula a continuidades do ponto de vista dos problemas que orientam a pesquisa, dos quais os estudos pós-coloniais e globais funcionam como uma espécie de espelho invertido das leituras racistas ou nacionalistas anteriores. Não se trata, certamente, de abandonar os debates herdados do passado; sua relevância é sintoma da continuidade de elementos estruturais da modernidade, tais como o capitalismo, o imperialismo e a integração em nível global. Antes, a discussão sobre sua historicidade deve servir tanto para a autocrítica da própria historiografia, quanto para a percepção da complexidade da realidade histórica, irredutível às ansiedades da formação e eventual colapso da hegemonia global ocidental nos últimos séculos.

\section{Referências bibliográficas}

ALCOCK, Susan E. Breaking up the Hellenistic world: survey and society. In: MORRIS, Ian (Org.). Classical Greece: ancient histories and modern archaeologies. Cambridge [England]; New York, NY, USA: Cambridge University Press, 1994. p. 171-190.

ALDROVANDI, Cibele Elisa Viegas. A morfogênese espacial da antiga Báctria: interações e paradigmas em uma paisagem fractal. Revista do Museu de Arqueologia e Etnologia, n. 20, p. 163, 9 dez. 2010.

ARRIGHI, Giovanni. O longo século XX: dinheiro, poder e as origens de nosso tempo. Tradução Vera Ribeiro. Rio de Janeiro; São Paulo: Contraponto Ed. UNESP., 2006.

BREUILLY, John. Nationalism, Power and Modernity in Nineteenth - Century Germany. London: German Historical Institute, 2007.

BREUILLY, John. The Formation of the First German Nation-State, 1800-1871. Houndmills: Palgrave, 2008.

BRIANT, Pierre. Alexandre et "hellénisation de l'Asie;. L'histoire au passé et au présent. Studi Ellenistici, v. 16, p. 9-69, 2005.

BRIANT, Pierre. Michael Rostovtzeff, Elias Bickerman and the "Hellenization of Asia": from Alexander the Great to WWII. Writing 
History in Time of War Michael Rostovtzeff, Elias Bickerman and the "Hellenization of Asia". Stuttgart: Franz Steiner Verlag, 2015.

BURSTEIN, Stanley Mayer. The world from 1000 BCE to 300 CE. New York, NY: Oxford University Press, 2017.

CANFORA, Luciano. Johann Gustav Droysen, Histoire de l'Hellénisme. Anabases. Traditions et réceptions de l'Antiquité, n. 5, p. 277-280, 1 mar. 2007.

GARDIN, Jean-Claude. Prospections archéologiques en Bactriane orientale (1974-1978). vol. 3, Description des sites et notes de synthèse. Paris: Ed. Recherche sur les civilisations, 1998.

GENTELLE, Pierre (1933-2010) Auteur Du texte. Prospections archéologiques en Bactriane orientale (1974-1978). vol. 1, Données paléogéographiques et fondements de l'irrigation: / par Pierre Gentelle; avec des contributions de Carmine Marinucci, Fabienne O. Vallino et Jean Trichet; cartogr. de Madeleine Sintes-Aioutz... Paris: De Boccard, 1989.

GUARINELLO, Norberto Luiz. Uma Morfologia da História: As Formas da História Antiga. Politeia: História e Sociedade, v. 3, n. 1, 2003.

HODOS, Tamar. Stage settings for a connected scene.: Globalization and material-culture studies in the early first-millennium B.C.E. Mediterranean. Archaeological Dialogues, v. 21, n. 1, p. 24-30, jun. 2014.

HOLT, Frank Lee. Thundering Zeus: the making of Hellenistic Bactria. Berkeley: University of California Press, 1999.

IGGERS, Georg G. The German Conception of History: The National Tradition of Historical Thought from Herder to the Present. [S.l.]: Wesleyan University Press, 2012.

KNUST, José Ernesto Moura. Os Pláucios, a emancipação da plebe e a expansão romana: conectando as histórias interna e externa da República Romana. Esboços: histórias em contextos globais, v. 26, n. 42, p. 234-254, 16 jul. 2019.

LITVINSKIY, B. A.; PICHIKIYAN, I. R. The Temple of the Oxus. Journal of the Royal Asiatic Society of Great Britain and Ireland, n. 2, p. 133-167, 1981.

LYONNET, Bertille. Prospections archéologiques en Bactriane orientale. 2, Céramique et peuplement du chalcolithique à la conquête arabe : 1974-1978. Paris: De Boccard, 1997. 
MAIRS, Rachel. Achaemenid Ai Khanoum. Archäologische Mitteilungen aus Iran und Turan, v. 46, 2014.

MAIRS, Rachel. The Hellenistic Far East: Archæology, Language, and Identity in Greek Central Asia. Berkeley: University of California Press, 2016.

MARTINEZ-SÈVE, Laurianne. Ai Khanoum and Greek Domination in Central Asia. ELECTRUM, v. 2015, n. Volume 22, p. 17-46, 22 dez. 2015.

MOMIGLIANO, Arnaldo. Niebuhr and the Agrarian Problems of Rome. History and Theory, v. 21, p. 3-15, 1982.

MORALES, Fabio Augusto. Graecia capta, novamente: considerações sobre os limites da nova romanização da Grécia. Revista do Museu de Arqueologia e Etnologia., v. Supp. 18, p. 91-97, 2014.

MORALES, Fabio Augusto. Niebuhr e a História Antiga no século XIX: experimentações morfológicas. Como se escreve a História da Antiguidade: olhares sobre o antigo. No prelo, p. 48-70.

MORALES, Fábio Augusto; PEREIRA, Mateus Henrique de Faria. O convite da história global. Esboços: histórias em contextos globais, v. 26, n. 41, p. 7-13, 30 jan. 2019.

MORALES, Fábio Augusto; SILVA, Uiran Gebara Da. História Antiga e História Global: afluentes e confluências. No prelo., 2019.

NIEBUHR, Barthold Georg. Lectures on ancient history, from the earliest times to the taking of Alexandria by Octavianus. Comprising the history of the Asiatic nations, the Egyptians, Greeks, Macedonians and Carthaginians, vol. 1. Tradução Leonhard Schmitz. Philadelphia: Philadelphia, Blanchard, 1852a.

NIEBUHR, Barthold Georg. Lectures on ancient history, from the earliest times to the taking of Alexandria by Octavianus. Comprising the history of the Asiatic nations, the Egyptians, Greeks, Macedonians and Carthaginians, vol. 2. Tradução Leonhard Schmitz. London: Taylor, Walton, Maberly, 1852b.

NIEBUHR, Barthold Georg. Lectures on ancient history, from the earliest times to the taking of Alexandria by Octavianus. Comprising the history of the Asiatic nations, the Egyptians, Greeks, Macedonians and Carthaginians, vol 3. Tradução Leonhard Schmitz. London: Taylor, Walton, Maberly, 1852c.

ROBERT, Louis. De Delphes à l'Oxus, inscriptions grecques nouvelles de la Bactriane. Comptes rendus des séances de l'Académie des Inscriptions et BellesLettres, v. 112, n. 3, p. 416-457, 1968. 
SCOPACASA, Rafael. Hegemonia romana e transformações culturais no mediterrâneo (séculos IV-II a. C.): novas perspectivas da história global. Revista de História, n. 177, p. 01-35, 23 maio 2018.

SILVEIRA, Aline Dias Da. Algumas experiências, perspectivas e desafios da Medievalística no Brasil frente às demandas atuais. Revista Brasileira de História, v. 36, n. 72, p. 39-59, 15 set. 2016.

VERHASSELT, Gertjan. The Seven Sages and the Inscription of Aï Khanoum. In: FORTENBAUGH, W.; MIRHADY, D. (eds). Clearchus of Soli: Text, Translation, and Discussion (RUSCH 21). New York: Routledge. [Forthcoming], p. 1-19.

VLASSOPOULOS, K. Greeks and Barbarians. Cambridge: Cambridge University Press, 2013.

. Does Slavery Have a History? The Consequences of a Global Approach. Journal of Global Slavery, v. 1, n. 1, p. 5-27, 2016.

THONEMANN, Peter. The Hellenistic age. First edition ed. Oxford, United Kingdom: Oxford University Press, 2016. 